\title{
Objectively identified comorbidities in COPD: impact on pulmonary rehabilitation outcomes
}

\author{
To the Editor:
}

Pulmonary rehabilitation (PR) is a comprehensive intervention recognised as a core component in the treatment of patients with chronic obstructive pulmonary disease (COPD) [1]. Comorbidities are highly prevalent in patients with COPD entering PR [2-4], which may be associated with the change in exercise performance and health status after PR [3-5]. Nonetheless, previous studies used self-reported and/or chart-based comorbidities, and only the impact of individual comorbidities or arbitrarily grouped comorbidities were studied $[3,4]$.

VAnfleteren et al. [2] identified five clusters based on the presence of 13 objectively diagnosed comorbidities in patients with COPD. The aims of the present study were: 1) to investigate the impact of 13 individual objectively identified comorbidities on changes in functional exercise performance and health status following PR in patients with COPD; and 2) to investigate the impact of the five comorbidity clusters on these changes.

Patients adhered to the following inclusion criteria: Global Initiative for Chronic Obstructive Lung Disease grades 2-4 [6], 40-80 years of age, clinically stable state, and a smoking history of $\geqslant 10$ pack-years or relevant occupational exposure. Patients were considered ineligible if they had any disease and/or condition that could compromise the initial assessments. All participants gave written informed consent, and the study was approved by the local ethics and review boards (MEC 10-3-067). The baseline data from this study have been published before [2].

Participants enrolled in an 8-week inpatient $\left(5\right.$ days·week ${ }^{-1}$ ) or 14 -week outpatient (3 days.week ${ }^{-1}$ ) comprehensive PR programme [7]. During initial evaluation, 13 comorbidities were diagnosed using objective measures and according to international criteria, and five comorbidity clusters were identified. Further details can be found in VANFLETEREN et al. [2]. Self-reported comorbidities were assessed using the Charlson comorbidity index [8]. The total score on this index was not adjusted for age and did not include COPD as comorbidity, as previously suggested $[3,4]$.

Functional exercise capacity (the 6-min walk test and the constant work rate cycling test (CWRT), performed on a cycle ergometer) and health status (St George's Respiratory Questionnaire (SGRQ)) were assessed before and after PR. An improvement in: the 6-min walking distance (6MWD) of $\geqslant 30 \mathrm{~m}$ [9]; the CWRT time of $\geqslant 100 \mathrm{~s}$ [10]; and a decrease in SGRQ total score of $\geqslant 4$ [11] were considered clinically relevant. Logistic regression models adjusted for age, sex, forced expiratory volume in the $1 \mathrm{~s}\left(\mathrm{FEV}_{1}\right)$ and the baseline 6MWD, CWRT time or SGRQ total score were used to identify the predictive role of comorbidities on meaningful improvements following PR. Statistical significance was considered at $\mathrm{p} \leqslant 0.01$.

255 patients with COPD were recruited, but 42 patients were ineligible [2]. 213 participants (59\% male, mean age $64 \pm 7$ years, mean FEV1 $51 \pm 17 \%$ predicted) started PR, of which 19 (9\%) participants dropped out. No differences were found between patients who dropped out and patients who completed the programme. The proportion of patients undergoing inpatient or outpatient rehabilitation was comparable between clusters $(\mathrm{p}=0.37)$.

The mean change $(95 \% \mathrm{CI})$ for $6 \mathrm{MWD}$, cycle endurance time, and health status scores were $30 \mathrm{~m}$ (23-38 m), $202 \mathrm{~s}(155-248 \mathrm{~s})$ and $-4.0(-6.0--2.0)$, respectively, and proved to be clinically meaningful and statistically significant. Logistic regression models revealed that none of the 13 objectively diagnosed comorbidities changed the likelihood for a clinically meaningful change in 6MWD, CWRT time or SGRQ total score following PR (fig. 1). When the number of objectively identified comorbidities (none, 1 and $>1$ ) were taken into account in logistic regression models, none of the analyses reached statistical significance (fig. 1). Similar results were found for the total score in the Charlson index $(0,1$ or $\geqslant 2$ points). With the "less comorbidity" cluster as reference, none of the clusters had a significantly different likelihood to achieve the minimal important change on the different outcomes. Only the "psychologic" cluster had a significantly higher likelihood for clinically meaningful change in 6MWD (fig. 1). 


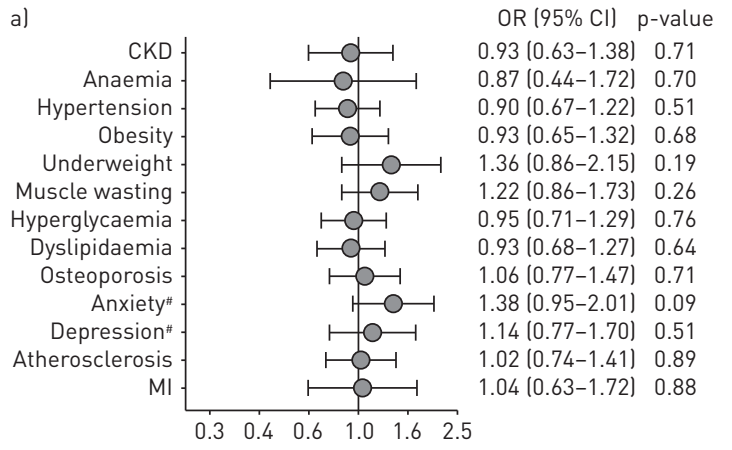

$\mathrm{OR}$
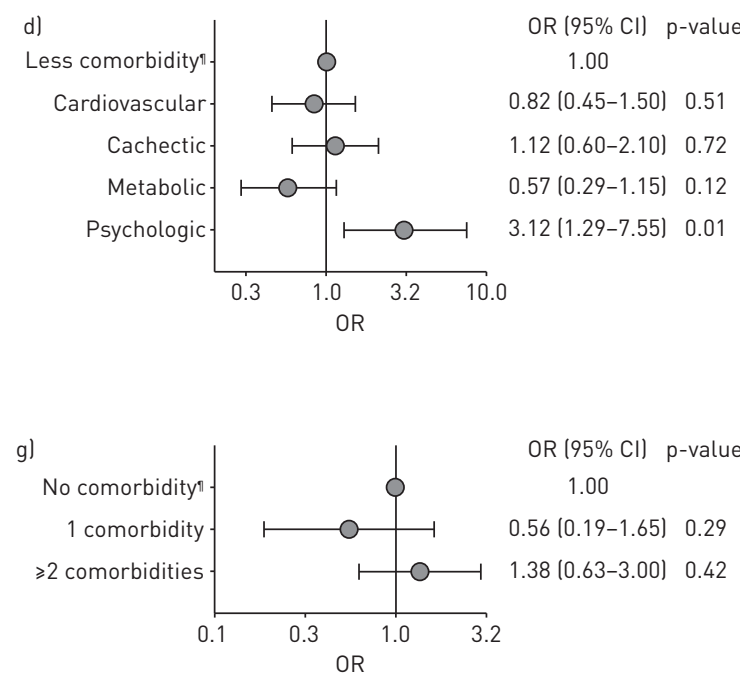

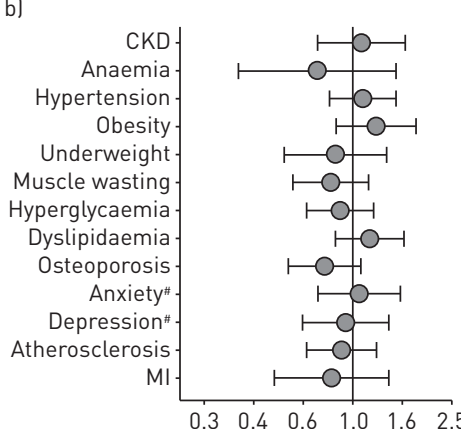

$\mathrm{OR}$
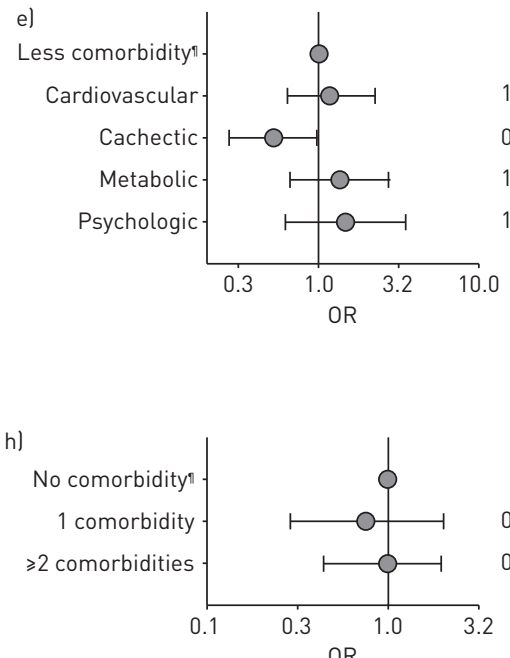
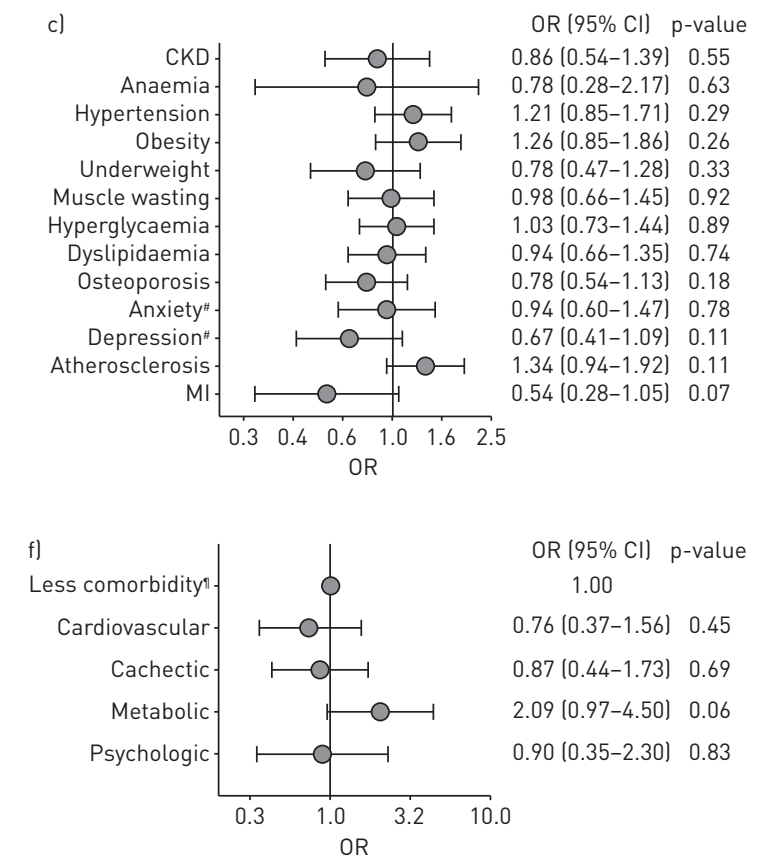

OR $(95 \%$ Cl) p-value

1.00

$0.76(0.37-1.56) \quad 0.45$

$0.87(0.44-1.73) \quad 0.69$

$2.09(0.97-4.50) \quad 0.06$

$0.90(0.35-2.30) \quad 0.83$

FIGURE 1 Predictive role of individual objectively identified comorbidities (a-c), clusters of objectively identified comorbidities (d-f), and the number of objectively identified comorbidities (h-i) on meaningful improvements, after pulmonary rehabilitation, in: a, d and g) the 6-min walk test ( $\mathrm{n}=187$ due to missing data); b, e and $\mathrm{h}$ ) constant work rate test ( $\mathrm{n}=174$ due to missing data); and $\mathrm{c}, \mathrm{f}$ and $\mathrm{g}$ ) St George's Respiratory Questionnaire ( $\mathrm{n}=151$ due to missing data). Models adjusted for age, sex, forced expiratory volume in $1 \mathrm{~s}$ and the baseline value in each outcome measure. CKD: chronic kidney disease; MI: myocardial infarction. "*: participants showing symptoms; ๆ: reference. 
The present study showed that the presence of individual or clusters of objectively identified comorbidities do not, generally, influence the likelihood of having a clinically meaningful change in 6MWD, CWRT time and/or SGRQ total score following PR in patients with COPD. These data emphasise that patients with COPD are still able to obtain significant and clinically relevant improvements in functional exercise capacity and health status after PR, irrespective of the presence of comorbidities.

Osteoporosis, heart disease and metabolic disease have been shown to be positively or negatively associated with changes in 6MWD and SGRQ scores following PR [3,4]. We were not able to corroborate these findings. In our study, comorbidities were assessed using objective measures, while most previous studies used "self-reports" or data from medical records [3, 4]. Moreover, previous studies used a different threshold to classify an improvement in 6MWD as clinically relevant (i.e. $54 \mathrm{~m})[3,4]$.

Surprisingly, only the "psychologic" cluster was associated with a higher likelihood of achieving meaningful improvements in 6MWD compared to the "less comorbidity" cluster. The "psychologic" cluster is characterised by more baseline symptoms of anxiety and depression [2]. Previously, VON LEUPOLDT et al. [12] showed that more symptoms of anxiety and depression are associated with reduced exercise capacity. We believe that more symptoms of anxiety and/or depression may lead to excessive sensitiveness to dyspnoea, which in turn can work as a limiting factor for exercise. As suggested by MAURER et al. [13], the multidisciplinary and comprehensive approach adopted in PR programmes may help to desensitise patients who are excessively sensitive to dyspnoea, and this can translate as greater improvements in terms of exercise capacity. A reduction of anxiety and depression symptom scores, commonly achieved after PR, may, in turn, contribute to dyspnoea desensitisation [13].

The presence of common comorbidities in patients with COPD has been used frequently as an exclusion criterion for PR [1]. In the present study, only patients with comorbidities potentially interfering with the safety or usefulness of the programme were excluded, such as unstable heart disease or uncurated malignancies. Our study proves that common comorbidities, in general, do not influence the likelihood of improving following PR. Moreover, exercise has been suggested as the cornerstone of PR in COPD [1], and this strategy has been used as therapy in other chronic diseases as well, such as cardiovascular and metabolic diseases $[14,15]$. Therefore, patients with COPD and the above mentioned comorbidities may benefit even more from PR.

The patients included in the current analysis were those referred for $\mathrm{PR}$, which can compromise the generalisability of our findings. Nevertheless, VANFLETEREN et al. [2] have previously shown that these patients have similar characteristic compared to patients from other studies. Another possible limitation is that some analyses may be underpowered. Therefore, the current findings are more hypothesis-generating than definitive. Studies with large samples and preferably from different centres are desirable.

In summary, comorbidities do not seem to preclude patients with COPD from obtaining significant and clinically meaningful improvements in functional exercise capacity and health status following PR. Complex patients with COPD and comorbidities should not be withheld from PR.

0 @ERSpublications

Patients with COPD and multiple comorbidities can still benefit from pulmonary rehabilitation http://ow.ly/LXAWc

Rafael Mesquita ${ }^{1,2,6}$, Lowie E.G.W. Vanfleteren ${ }^{1,2,6}$, Frits M.E. Franssen ${ }^{1,2}$, Janeli Sarv ${ }^{3}$, Ziad Taib ${ }^{3}$, Miriam T.J. Groenen ${ }^{1}$, Swetlana Gaffron ${ }^{4}$, Piet L.B. Bruijnzeel ${ }^{3}$, Fabio Pitta ${ }^{5}$, Emiel F.M. Wouters ${ }^{1,2}$ and Martijn A. Spruit ${ }^{1}$

${ }^{1}$ Dept of Research and Education, Centre of Expertise for Chronic Organ Failure (CIRO+), Horn, The Netherlands. ${ }^{2}$ Dept of Respiratory Medicine, Maastricht University Medical Centre (MUMC+), Maastricht, The Netherlands. ${ }^{3}$ Respiratory, Infections and Autoimmunity (RIA) IMED, AstraZeneca, Mölndal, Sweden. ${ }^{4}$ Analytics, Viscovery Software $\mathrm{GmbH}$, Vienna, Austria. ${ }^{5}$ Laboratory of Research in Respiratory Physiotherapy, Dept of Physiotherapy, State University of Londrina (UEL), Londrina, Brazil. ${ }^{6}$ Both authors contributed equally.

Correspondence: Rafael Mesquita, Dept of Research \& Education, CIRO+, Center of Expertise for Chronic Organ Failure, Hornerheide 1, 6085 NM, Horn, The Netherlands. E-mail: rafaelmesquita14@ymail.com

Received: Jan 212015 | Accepted after revision: April 06 2015 | First published online: June 252015

Support statement: R. Mesquita is supported by CNPq, Conselho Nacional de Desenvolvimento Científico e Tecnológico - Brazil (246704/2012-8). This study was supported by a research grant from AstraZeneca. Funding information for this article has been deposited with FundRef.

Conflict of interest: Disclosures can be found alongside the online version of this article at erj.ersjournals.com 


\section{References}

1 Spruit MA, Singh SJ, Garvey C, et al. An official American Thoracic Society/European Respiratory Society statement: key concepts and advances in pulmonary rehabilitation. Am J Respir Crit Care Med 2013; 188: e13-e64.

2 Vanfleteren LE, Spruit MA, Groenen M, et al. Clusters of comorbidities based on validated objective measurements and systemic inflammation in patients with chronic obstructive pulmonary disease. Am J Respir Crit Care Med 2013; 187: 728-735.

3 Crisafulli E, Costi S, Luppi F, et al. Role of comorbidities in a cohort of patients with COPD undergoing pulmonary rehabilitation. Thorax 2008; 63: 487-492.

4 Crisafulli E, Gorgone P, Vagaggini B, et al. Efficacy of standard rehabilitation in COPD outpatients with comorbidities. Eur Respir J 2010; 36: 1042-1048.

5 Ambrosino N, Venturelli E, de Blasio F, et al. A prospective multicentric study of pulmonary rehabilitation in patients with chronic obstructive pulmonary disease and different clinical phenotypes. Respiration 2015; 89: 141-147.

6 Vestbo J, Hurd SS, Agusti AG, et al. Global strategy for the diagnosis, management, and prevention of chronic obstructive pulmonary disease: GOLD executive summary. Am J Respir Crit Care Med 2013; 187: 347-365.

7 Spruit MA, Vanderhoven-Augustin I, Janssen PP, et al. Integration of pulmonary rehabilitation in COPD. Lancet 2008; 371: 12-13.

8 Charlson ME, Pompei P, Ales KL, et al. A new method of classifying prognostic comorbidity in longitudinal studies: development and validation. J Chronic Dis 1987; 40: 373-383.

9 Holland AE, Spruit MA, Troosters T, et al. An official European Respiratory Society/American Thoracic Society technical standard: field walking tests in chronic respiratory disease. Eur Respir J 2014; 44: 1428-1446.

10 Laviolette L, Bourbeau J, Bernard S, et al. Assessing the impact of pulmonary rehabilitation on functional status in COPD. Thorax 2008; 63: 115-121.

11 Jones PW. St George's Respiratory Questionnaire: MCID. COPD 2005; 2: 75-79.

12 von Leupoldt A, Taube K, Lehmann $\mathrm{K}$, et al. The impact of anxiety and depression on outcomes of pulmonary rehabilitation in patients with COPD. Chest 2011; 140: 730-736.

13 Maurer J, Rebbapragada V, Borson S, et al. Anxiety and depression in COPD: current understanding, unanswered questions, and research needs. Chest 2008; 134: 43S-56S.

14 Mezzani A, Hamm LF, Jones AM, et al. Aerobic exercise intensity assessment and prescription in cardiac rehabilitation: a joint position statement of the European Association for Cardiovascular Prevention and Rehabilitation, the American Association of Cardiovascular and Pulmonary Rehabilitation, and the Canadian Association of Cardiac Rehabilitation. J Cardiopulm Rehabil Prev 2012; 32: 327-350.

15 O’Hagan C, De Vito G, Boreham CA. Exercise prescription in the treatment of type 2 diabetes mellitus: current practices, existing guidelines and future directions. Sports Med 2013; 43: 39-49.

\section{Safety and efficacy of auto-titrating noninvasive ventilation in COPD and obstructive sleep apnoea overlap syndrome}

\section{To the Editor:}

The deleterious effects of comorbid chronic obstructive pulmonary disease (COPD) and obstructive sleep apnoea (OSA) have long been recognised and are frequently encountered as a clinical scenario [1, 2]. Although continuous positive airways pressure can be used in order to abolish upper airways obstruction in OSA, it can have adverse effects on pulmonary mechanics in patients with airways obstruction [3]. Auto-titrating modes of noninvasive ventilation (NIV) that monitor tidal volume, respiratory rate and upper airway patency and can vary back up rate, inspiratory and expiratory positive airway pressure (IPAP and EPAP, respectively) may have clinical benefits. However, these auto-titration modes and the software algorithms driving the ventilators are being engineered and modified at a rapid rate. The clinician, therefore, needs to be reassured that these novel modes have an established safety and efficacy profile. We hypothesised that auto-titrating NIV would enhance overnight gas exchange, sleep quality, and patient comfort when compared to standard fixed-level NIV in COPD-OSA patients with chronic respiratory failure.

A phase 2 open-labelled sequential treatment design recruited patients from two established home ventilation centres. 10 patients were required to achieve a power of $80 \%$ at a $p=0.05$, assuming a standard deviation of $0.5 \mathrm{kPa}$, to demonstrate a $0.5 \mathrm{kPa}$ difference in mean nocturnal transcutaneous carbon dioxide tension $\left(\mathrm{PtcCO}_{2}\right)$ from fixed to auto-titrating NIV. Local research ethics approval was obtained (11/LO/1627) and the trial was registered on the ClinicalTrials.gov database with identifier number: NCT01601977. 